\title{
Abdominal Pain, Hyperkalemia, and Elevated Creatinine after Blunt Trauma: Bladder Rupture and Pseudo-Acute Kidney Injury
}

By Reza D Mirza MD, Eric KC Wong MD FRCPC, Robert Yang MD FRCPC, Catherine M Clase MB MSc FRCPC

DOI: 10.22374/cjgim.v13i2.229

\section{About the Authors}

Reza Mirza, Robert Yang and Catherine Clase are with the Department of Medicine, McMaster University. Catherine Clase is also with the Department of Clinical Epidemiology and Biostatistics, McMaster University. Eric Wong is with the Department of Medicine, University of Toronto.

Corresponding Author Catherine Clase: clase@mcmaster.ca

Submitted: July 29, 2017; Accepted: November 26, 2017. Published: June 25, 2018.

\begin{abstract}
A 40-year-old man involved in trauma presented with abdominal pain and ascites. He was referred to nephrology for elevated creatinine and hyperkalemia. Initial imaging showed diffuse free fluid in the abdomen and pelvis without solid organ injury. Paracentesis drained 1.5L of yellow fluid notable for a creatinine of $2259 \mu \mathrm{mol} / \mathrm{L}$. Intraperitoneal urinary bladder rupture was diagnosed and surgically repaired. Within 24 hours, creatinine had normalized consistent with a presentation of pseudo-acute-kidney-injury. This case and a literature review reveals that this condition is often delayed in diagnosis or misdiagnosed altogether.

\section{RESUME}

Un homme de 40 ans impliqué dans un traumatisme s'est présenté avec des douleurs abdominales et une ascite. Il a été référé à la néphrologie pour une créatinine et une hyperkaliémie élevées. L'imagerie initiale a montré un fluide libre diffus dans l'abdomen et le bassin sans lésion des organes solides. La paracentèse a drainé $1,5 \mathrm{~L}$ de liquide jaune notable pour une créatinine de $2259 \mu \mathrm{mol} / \mathrm{L}$. La rupture de la vessie par voie intrapéritonéale a été diagnostiquée et réparée chirurgicalement. Dans les 24 heures, la créatininémie s'est normalisée en présence d'une atteinte pseudo-aiguë-rénale. Ce cas et une révision de la littérature révèlent que cette maladie est souvent retardée dans le diagnostic ou mal diagnostiquée.
\end{abstract}

\section{Case}

A 40-year-old Caucasian male presented to a southern Ontario community hospital 3 days after an altercation, during which he was punched, thrown to the ground, stamped on, and kicked. One day after the incident, he stopped urinating. Three days after the incident, he woke up with abdominal distention, increased suprapubic pain, and experienced more than 30 episodes of coffee-ground emesis. He had 7 episodes of rectal bleeding, after which he stopped passing stool.

His medical history was non-contributory. There was no history of renal or urologic problems. There was no history of malignancy or pelvic radiation.

On initial presentation, his serum creatinine was $987 \mu \mathrm{mol} / \mathrm{L}$, urea $34.2 \mathrm{mmol} / \mathrm{L}$, and potassium $7.1 \mathrm{mmol} / \mathrm{L}$ (non-hemolyzed). 
An unenhanced computed tomography (CT) showed diffuse free fluid in the abdomen and pelvis with a density less than 10 Hounsfield units, suggesting non-bloody fluid (Figure 1). ${ }^{1}$ No solid organ injury or hydronephrosis was visualized. Bladder catheterization immediately produced $2 \mathrm{~L}$ of urine. A paracentesis drained an additional $1.5 \mathrm{~L}$ of yellow fluid with creatinine of 2259 $\mu \mathrm{mol} / \mathrm{L}$ suggesting urine in the peritoneal cavity. The patient was also given 10 units of insulin and dextrose; serum potassium fell to $6.1 \mathrm{mmol} / \mathrm{L}$. The patient was then given a tetanus vaccine and transferred to our tertiary centre with cardiac monitoring.

At referral, the nephrology team was consulted. The patient was afebrile with a heart rate of 94 , blood pressure of 131/81 and oxygen saturation of $95 \%$ on $2 \mathrm{~L}$ of oxygen via nasal cannula. He had a peritoneal drain and a urinary catheter that had drained $6.5 \mathrm{~L}$ of clear yellow fluid over the previous several hours. His abdomen was no longer distended and was soft but mildly tender in the lower quadrants. He also had multiple bruises and lacerations.

Repeat bloodwork revealed serum creatinine of $946 \mu \mathrm{mol} / \mathrm{L}$ and urea $35.8 \mathrm{mmol} / \mathrm{L}$. Hemoglobin was $119 \mathrm{~g} / \mathrm{L}$, white blood cell count $11.2 \times 10^{9} / \mathrm{L}$ and platelets $222 \times 10^{9} / \mathrm{L}$. Serum sodium was $125 \mathrm{mmol} / \mathrm{L}$, chloride $93 \mathrm{mmol} / \mathrm{L}$, bicarbonate $16 \mathrm{mmol} / \mathrm{L}$, and potassium was $5.4 \mathrm{mmol} / \mathrm{L}$.

Bladder rupture was diagnosed and the urology team took the patient for emergent exploratory laparotomy. A $2 \mathrm{~cm}$ perforation found in the bladder dome was closed. A suprapubic catheter was inserted.

Creatinine level dropped precipitously from $946 \mu \mathrm{mol} / \mathrm{L}$ to $509 \mu \mathrm{mol} / \mathrm{L}$ post-laparotomy approximately 5 hours later, then to $220 \mu \mathrm{mol} / \mathrm{L} 10$ hours later. The following morning the patient's creatinine was $56 \mu \mathrm{mol} / \mathrm{L}$ and remained stable until discharge.

The patient gave informed consent for this anonymized account.

\section{Discussion}

This is a classic presentation of bladder rupture causing an elevated creatinine level not from acute kidney injury (AKI, i.e., fall in glomerular filtration rate), but from autodialysis of urine ascitic fluid. This has been termed pseudo-AKI or pseudo-renal failure to highlight the absence of renal injury. ${ }^{2}$ Diffusion of creatinine, urea and potassium across the peritoneal membrane from the urine in the peritoneum results in elevated serum values.

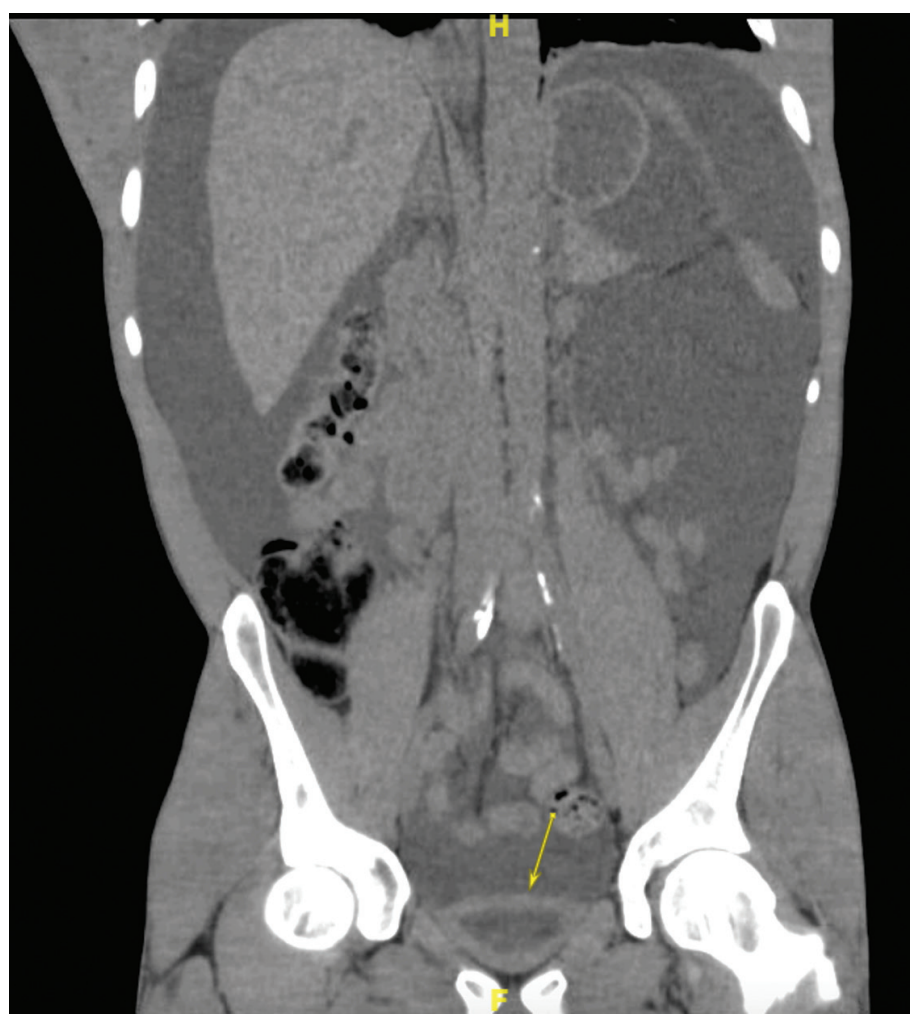

Figure 1. Abdominal and pelvic computed tomography at the time of presentation to the primary hospital. Reported as limited study, particularly of solid organs, given lack of contrast. Contrast was not given due to due to elevated creatinine. Findings: diffuse free fluid, unremarkable bladder. 
We conducted a systematic review (see methodology in Appendix) and found 40 case reports and 2 case series with 2 patients each. Half of the cases (51\%) were caused by trauma. Iatrogenic causes accounted for the other half (49\%), typically after gynecologic procedures, followed by general surgical, then urologic. Less than $1 \%$ of cases were caused by alcohol-induced ruptures - typically a mixed picture of a full bladder and falls - and spontaneous ruptures in patients with obstructive or retentive pathologies.

The bladder is a subperitoneal organ located in the pelvis with its dome bordering the peritoneal cavity. Bladder ruptures can be broken down into 3 types depending on the site of urine extravasation: intraperitoneal, extraperitoneal, and combined. ${ }^{3}$

Extraperitoneal ruptures occur in $54-56 \%$ of cases $^{3}$ and almost exclusively in blunt traumas that fracture the pelvic bone. ${ }^{4}$ Intraperitoneal bladder ruptures (38-40\% of cases) are caused by a surge in intravesicular pressure resulting in dome rupture, the most mobile and vulnerable part of the bladder. ${ }^{3}$ This typically occurs when the bladder is full, pushing the bladder dome above the pelvic inlet and exposing it. ${ }^{4}$ As in our patient, pseudo-AKI occurs as a result of an intraperitoneal bladder rupture. Patients clinically present with abdominal pain, accumulating urinary ascites, and oligo-anuria. Late presentations include ileus, peritonitis, ${ }^{5}$ and sepsis. ${ }^{3}$

Intraperitoneal bladder rupture may lead to elevated creatinine, azotemia, hyperkalemia and hyponatremia suggestive of AKI. ${ }^{6}$ This, however, is not universal and is dependent on 2 factors: volume and time. Animal experiments show larger volumes of urine in the bladder at rupture is associated with biochemical abnormalities occurring more quickly. ${ }^{7}$ Additionally, abnormalities are more pronounced in patients who present late after injury. As in our case, bladder ruptures often go unrecognized: the mean diagnostic delay in one series was 5.4 days. $^{8}$

The diagnostic test of choice is $\mathrm{CT}^{9}$ or static cystogram, but the diagnosis can be presumed in the presence of ascites with chemical characteristics of urine. Retrograde instillation of dilute contrast into the bladder is necessary to identify injury. ${ }^{10,11}$ Following diagnosis, urology consultation is required for definitive surgery.

\section{Conclusion}

We hope to raise awareness of the possibility of bladder rupture in patients presenting with oliguria and apparent AKI after trauma. Abdominal pain and ascites may also be evident. Our patient presented late after injury with a full constellation of findings. Bladder ruptures are often not considered initially, which may lead to dialysis treatments that were avoidable, to increased hospital stay, and increased morbidity.

\section{Funding}

No funding was received for this study.

\section{Conflicts of Interest}

None to report.

\section{REFERENCES}

1. Zech WD, Jackowski C, Buetikofer Y, Kara L. Characterization and differentiation of body fluids, putrefaction fluid, and blood using Hounsfield unit in postmortem CT. Int J Legal Med 2014;128:795-802. doi:10.1007/ s00414-014-1030-0.

2. Dees A, Kluchert SA, Van Vliet ACM. Pseudo-renal failure associated with internal leakage of urine. Neth J Med 1990;37:197-201.

3. Gomez RG, Ceballos L, Coburn M, Corriere JN, Dixon CM, Lobel B, et al. Consensus statement on bladder injuries. BJU Int 2004;94:27-32. doi:10.1111/j.1464-410X.2004.04896.x.

4. Corriere JN, Sandler CM. Management of the ruptured bladder: seven years of experience with 111 cases. J Trauma 1986;26:830-3. doi:10.1097/00005373-198609000-00009.

5. Tabaru A, Endou M, Miura Y, Otsuki M. Generalized peritonitis caused by spontaneous intraperitoneal rupture of the urinary bladder. Intern Med 1996;35:880-2.

6. Chow KM, Lam CM, Szeto CC. Pseudo-renal failure following total abdominal hysterectomy. J Nephrol 2005;18:442-6.

7. Shah PM, Kim KH, Ramirez-Schon G, Reynolds BM. Elevated blood urea nitrogen: an aid to the diagnosis of intraperitoneal rupture of the bladder. J Urol 1979;122:741-3.

8. Mokoena T, Naidu AG. Diagnostic difficulties in patients with a ruptured bladder. Br J Surg 1995;82:69-70. doi:10.1002/bjs.1800820124.

9. Chan DPN, Abujudeh HH, Cushing GL, Novelline RA. CT cystography with multiplanar reformation for suspected bladder rupture: Experience in 234 cases. Am J Roentgenol 2006;187:1296-302. doi:10.2214/AJR.05.0971.

10. Horstman WG, McClennan BL, Heiken JP. Comparison of computed tomography and conventional cystography for detection of traumatic bladder rupture. Urol Radiol 1990;12:188-93. doi:10.1007/BF02924005.

11. Mee SL, McAninch JW, Federle MP. Computerized tomography in bladder rupture: diagnostic limitations. J Urol 1987;137:207-9. doi:10.1016/0736-4679(87)90165-X.

\section{Appendix}

We conducted a systematic review of the literature from 1996 to January 29, 2016 using EMBASE and MEDLINE for cases of AKI with bladder injury in adults. The terms "acute kidney injury OR acute renal failure," "bladder OR urinary bladder," and "rupture OR trauma OR perforation OR bladder injury" were used to find reports from the past 20 years. We found 91 unique records and excluded 41 irrelevant citations and 4 cases in children $(<18$ y). The majority are case reports $(n=40)$; there were also 2 case series of a total of 4 further patients. 